\title{
Mechanical and durability properties of the concrete with copper slag
}

\author{
S. Jagan (Main Author, Corresponding Author) \\ Faculty of Civil Engineering, Kalasalingam Academy of Research and Education, Anand Nagar, Krishnankoil \\ 626126 (India) \\ s.jagan@klu.ac.in \\ https://orcid.org/0000-0002-4196-7803
}

\section{T.R. Neelakantan}

Faculty of Civil Engineering, Kalasalingam Academy of Research and Education, Anand Nagar, Krishnankoil 626126 (India)

Neelakantan@klu.ac.in

https://orcid.org/0000-0001-5721-3398

\section{R. Gokul Kannan}

Apprenticeship, Public works department, Tamilnadu public service commission, Theni, Tamilnadu, India 625531 (India)

Gokulcivil1212@gmail.com

Manuscript Code: 28261

Date of Acceptance/Reception: 13.08.2021/06.02.2021

DOI: 10.7764/RDLC.20.2.359

\section{Abstract}

Increased Development in the field of construction with the use of sand, stones etc. depletes the natural resources and thus resulted in the scarcity of construction materials. Furthermore, generation of waste from several industries such as steel slag, copper slag, blast furnace slag etc. are being dumped in the nearby landfills leading to disposal problems. The scarcity of construction materials necessitated the utilization of suitable alternative materials with equivalent physical and chemical characteristics. This paper investigates the suitability of copper slag (CS) as a substitute to natural fine aggregate (NFA) in the concrete. The concrete mixes are prepared with $0 \%, 10 \%, 30 \%, 50 \%, 70 \%$ and $100 \%$ of copper slag at $0.45 \mathrm{w} / \mathrm{c}$ ratio. The behaviour of CS in the concrete was assessed by hardened properties such as compression, tension and flexure at 7, 14, 28 and 90 days and durability properties such as water absorption, porosity and chloride ion penetration at 56 days. Results indicate that the replacement of CS beyond $50 \%$ affects properties of the concrete; however increased curing improved the properties of the concrete at higher replacement levels. Characterization studies such as XRD and SEM was performed to examine the effect of CS on the properties of the concrete.

Keywords: copper slag; natural fine aggregate; strength; durability; XRD and SEM.

\section{Introduction}

Concrete is a flexible material consumed at increased rate for the erection of architectural buildings, higher rise buildings and used in the construction of structural members, highways, railways, air ways etc (Jabri et al. 2009, Tamilselvi et al. 2009). The current dispute faced by the construction industries in recent times is the scarcity and increase in the cost of the construction materials. The concrete mixture comprises of cement, NFA, natural coarse aggregate (NCA) and water in which aggregates comprises nearly $70 \%$ of the concrete proportions. Perhaps, the accessibility of these aggregates is reducing rapidly due to several environmental concerns and human interventions. Conversely, the generation of wastes from the industries was increasing leading to disposal problems. The industries either dump the untreated wastes in the open field or discharge into the water bodies. The above disposal methods might cause considerable hazard to the environment and high threat to the aquatic lives and human health.

The current researchers focus on the sustainability and effective utilization of the available resources to overcome the scarcity of construction materials. Utilization of industrial waste would be an optimal solution under such circumstances but it would be trivial if the characteristics of the industrial waste were not equivalent to the material to be replaced. In previous studies, industrial waste such as coal ash, iron waste, smelting furnace slag, recycled glass etc. have been used as substitute to NFA in the concrete (Onprom et al. 2015, Ghafoori et al. 1996, Aggarwal et al. 2007, Andrade et al. 2009, Bai et al. 2005, Zhu et al. 2015, Tripathi et al. 2016, Al-Bawi et al. 2017). CS is one such industrial waste generated during the production of the copper. Nearly 2-3 tons of CS was generated during the production of 1 ton of copper. Figure 1(a) shows the leading producers of CS around the world and Figure 1(b) shows the percentage distribution of copper slag production across different continents. 
Figure 1.(a) Production of CS around the globe (b) percentage distribution of copper slag. (Self-Elaboration).

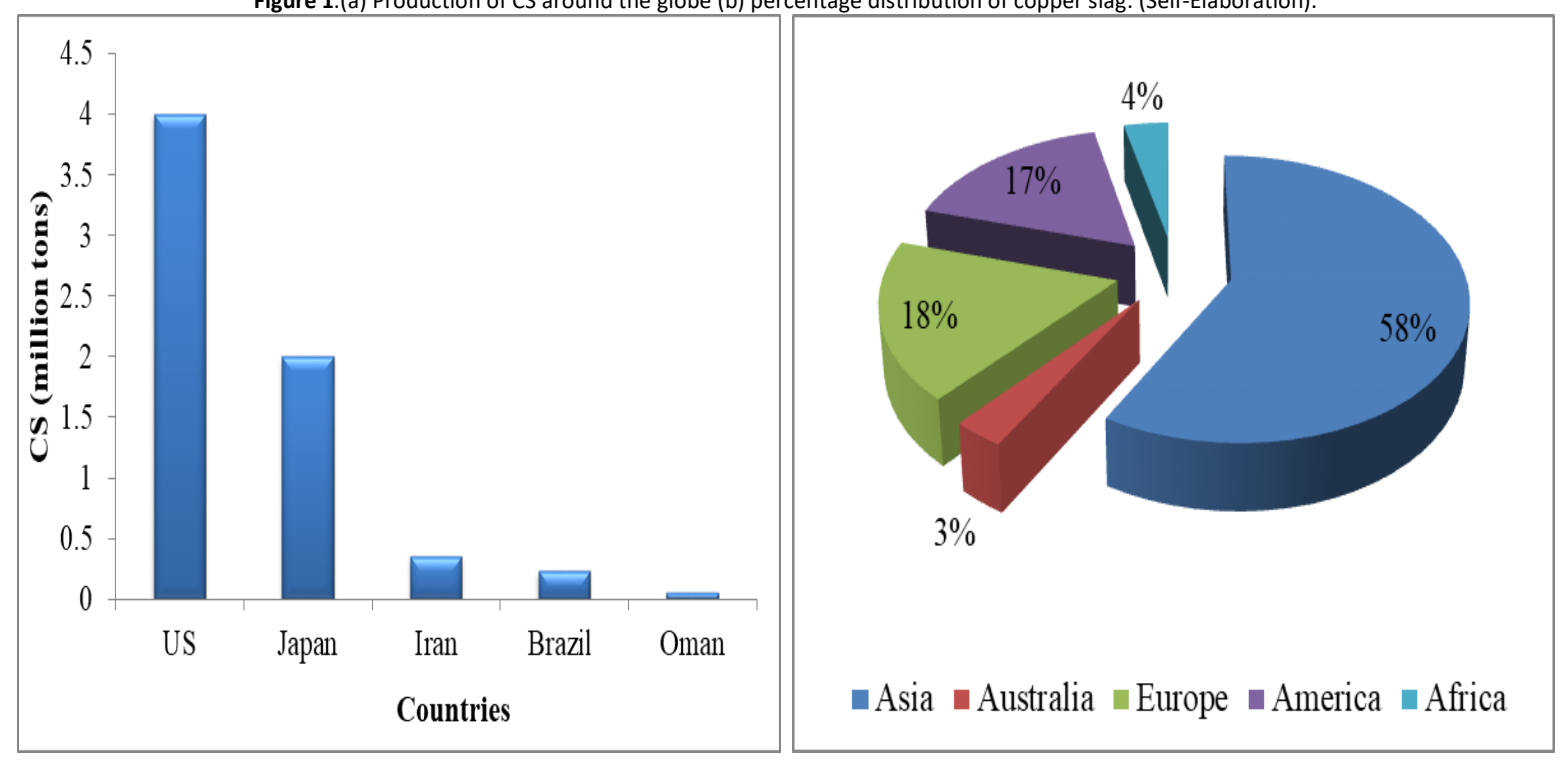

It could be observed that huge quantities of CS were generated every year around the world, in which disposal of such waste is a huge task. Various research have been performed to utilize the CS in the production of concrete with strength and durability requirements. (Gokce et al. 2021) replaced cement with $10 \%, 20 \%, 30 \%$, and $40 \%$ of blast furnace slag and added $10 \%, 15 \%, 20 \%$, and $25 \%$ of clacite by weight of cement to prepare a self compacting concrete (SCC) mixture. The results indicate that optimal SCC mixes are obtained with mixes containing either $20 \%$ and $25 \%$ of calcite to $30 \%$ and $40 \%$ of blast furnace slag. (Bingol et al. 2020) exposed the geopolymer mortars with ground granulated blast furnace slag (GGBFS) having 4,8 and $12 \%$ of Na concentration to acidic environment.

The results indicate that less strength reduction of $21 \%$ was obsereved with alkali activated slag prepared with $4 \%$ and $8 \%$ of Na concentration. (Tamilselvi et al. 2014) replaced NFA with $20 \%, 40 \%, 60 \%, 80 \%$ and $100 \%$ of CS and observed that optimal replacement of CS as $40 \%$. Results indicate that the strength of the concrete was reduced by $35.62 \%$ upon replacement of CS beyond $40 \%$ due to the lower water absorption of the CS. (Bhoi et al. 2018) studied the viability of using CS as a substitution to NFA and observed that the replacement of CS beyond $60 \%$ reduces the strength of the concrete and also the concrete mixes prepared at $0.36 \mathrm{w} / \mathrm{c}$ ratio with $60 \%$ of CS exhibited higher strength among all other mixes. (Al-Jabri et al. 2006) used CS in the preparation of high performance concrete and observed that higher replacement of CS increases the segregation and bleeding in the concrete due to its lower water absorption characteristics and thus reducing the strength of the concrete. Similarly, (Al-Jabri et al. 2011) studied the influence of CS on the properties of mortar and concrete and recommended that substitution of NFA by $40-50 \%$ of CS improved the strength and durability properties of the concrete. (Prem et al. 2018) produced sustainable concrete with high volume of CS at $0.57,0.47$ and $0.37 \mathrm{w} / \mathrm{c}$ ratios.

Results indicate that the chloride penetration and sorptivity was not increased with increase in the CS and the flexural capacity of the reinforced beam was improved with the addition of CS. (Kranti et al. 2020) observed that 100\% utilization of CS reduces the strength of the concrete by $11.38 \%$ and maximum weight loss occurs for the concrete mixtures with CS beyond $40 \%$ when subjected to acid attack. (Patil et al. 2021) used CS and granite dust as substitution to NFA and observed that mix with $60 \%$ of NFA $+20 \%$ of CS $+20 \%$ of granite dust shows $17.4 \%$ increase in the strength compared to control specimens at 28 days, but signifcant increase in the permeability beyond $30 \%$ of CS is also observed. (Mahesbabu et al. 2019) used CS with different percentages of nano-silica and examined that use of $100 \%$ CS with $1 \%$ of NS improved the strength from $87.18 \mathrm{MPa}$ to $98.87 \mathrm{MPa}$ and thus recommending the possibility of $100 \%$ utilization CS in the concrete. (Ambily et al. 2015) used CS in the production of ultra high performance concrete and observed that the strength decreases by $15-25 \%$ at 28 days compared to control concrete and a mean compressive strength of 150 MPa was also oberved.

From the literature study, it is observed that low water absorption characteristics of CS increased the segregation and bleeding and thus reducing the replacement of CS in the concrete. In this research, the concrete mixtures are prepared by normal mixing approach with $10 \%, 30 \%, 50 \%, 70 \%$ and $100 \%$ of CS at $0.45 \mathrm{w} / \mathrm{c}$ ratios. The behaviour of the CS in the concrete was evaluated by hardened properties such as compression, tension, flexure and elastic modulus at 7, 14, 28 
and 90 days and durability properties such as water absorption, porosity and chloride ion penetration at 56 days respectively.

Materials and methods

\section{Materials}

Ordinary 43 grade OPC, NFA of $1.18 \mathrm{~mm} \sim 2.36 \mathrm{~mm}$, CS of $1.18 \mathrm{~mm} \sim 2.36 \mathrm{~mm}$, NCA of $10 \mathrm{~mm} 20 \mathrm{~mm}$ and water were used for the concrete production. The visual observation of NFA and CS is shown in the Figure 2. The CS was procured from the sterlite industry, India. The physical and chemical properties of OPC used in the study are shown in the Table 1.The chemical composition of CS used in the study was given in the table 2. From the Table 2, it is observed that total oxide composition goes beyond 70\% as in accordance with ASTM C 618 (1999). The physical properties of CS and NFA used in the study were given in the Table 3. The CS was allowed to pass through series of sieves to achieve effective particle distribution with the NFA used in the study. The particle packing analysis of CS and NFA is shown in the Figure 3.

Table 1. Physical and chemical properties of OPC. (Self-Elaboration).

\begin{tabular}{llc}
\hline S. No & Tests & Obtained Values \\
\hline 1 & Initial setting time of cement & 28 minutes \\
2 & Final setting time of cement & 537 minutes \\
3 & compressive strength & $43.75 \mathrm{MPa}$ \\
4 & Specific surface area & $276 \mathrm{~m}^{2} / \mathrm{kg}$ \\
5 & Loss on Ignition (LOI) & $3.61 \%$ \\
6 & Magnesia & $4.15 \%$ \\
7 & Insoluble residue & $2.25 \%$ \\
8 & Sulphuric anhydride & $3.24 \%$ \\
9 & Total chloride content $_{10}$ & $0.03 \%$ \\
10 & $\mathrm{CaO}_{-} \mathrm{SiO}_{2}+\mathrm{Al}_{2} \mathrm{O}_{3}+\mathrm{Fe}_{2} \mathrm{O}_{3}$ & $0.78 \%$ \\
11 & $\mathrm{Al}_{2} \mathrm{O}_{3} / \mathrm{Fe}_{2} \mathrm{O}_{3}$ & $1.24 \%$ \\
\hline
\end{tabular}

Table 2.Chemical composition of CS. (Self-Elaboration).

\begin{tabular}{lll}
\hline S. No & Oxide elements & Percentage \\
\hline 1 & $\mathrm{CaO}$ & 9.9 \\
2 & $\mathrm{SiO}_{2}$ & 33.09 \\
3 & $\mathrm{Al}_{2} \mathrm{O}_{3}$ & 2.61 \\
4 & $\mathrm{Fe}_{2} \mathrm{O}_{3}$ & 54.14 \\
\hline
\end{tabular}

\begin{tabular}{llll}
\multicolumn{4}{c}{ Table 3.Physical properties of CS and NFA. (Self-Elaboration). } \\
\hline S. No & Property & CS & NFA \\
\hline 1 & Specific gravity & 3.67 & 2.76 \\
2 & Density $\left(\mathrm{kg} / \mathrm{m}^{3}\right)$ & 1887 & 1709 \\
3 & Water absorption (\%) & 0.41 & 1.5 \\
4 & Fineness modulus & 3.22 & 3.10 \\
\hline
\end{tabular}



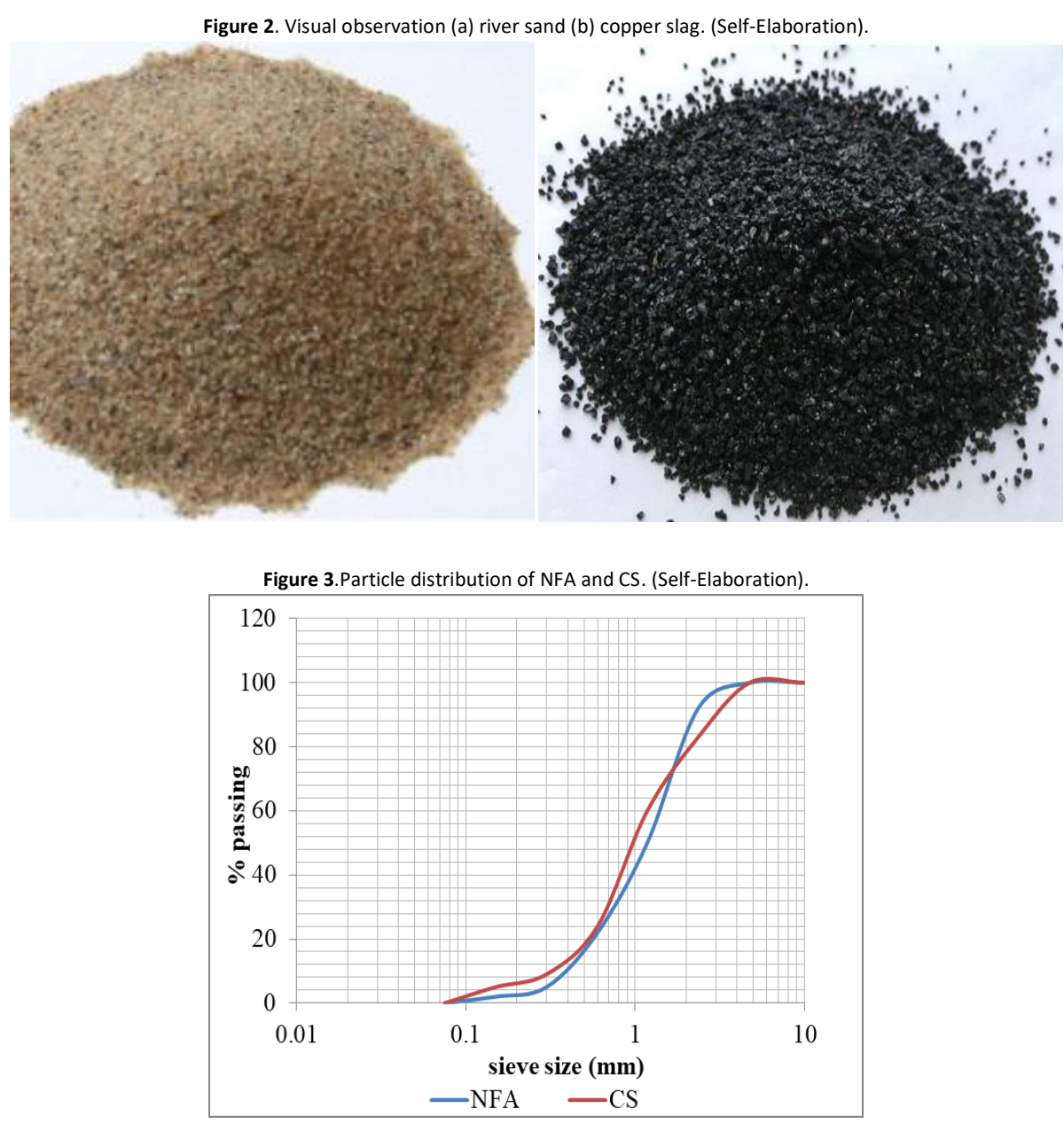

\section{Methods}

The details of the mix proportions adopted in the study is shown in the Table 4. The concrete mix prepared with cement, NFA, NCA and water was marked as control specimen (CC). The concrete mix prepared with $10 \%, 30 \%, 50 \%, 70 \%$ and $100 \%$ of CS was marked as CS $-10, C S-30, C S-50, C S-70$ and CS -100 . The concrete mix prepared by normal mixing approach (Figure 4) was tested for its fresh property by compaction factor test as per B.S: 1882 Part 2. The density of the hardened concrete specimens at 28 days was determined as per IS 2386 (part 3) (1963). The compression test was performed on $150 \mathrm{~mm}$ cubes in accordance with IS 516 (1959). The flexure test was performed on $500 \mathrm{~mm} \times 100 \mathrm{~mm} x$ $100 \mathrm{~mm}$ prisms in accordance with ASTM C39 / C39M - 20.

The tension test was performed on $150 \mathrm{~mm}$ x $300 \mathrm{~mm}$ cylinders in accordance with IS 5816 (1999). The water absorption and porosity of the concrete was determined at 56 days in accordance with ASTMC642-13 (2013). The rate of chloride ingression was determined on $100 \mathrm{~mm}$ x $200 \mathrm{~mm}$ discs in accordance with ASTM C 1202 at 28 days. All the tests are performed in laboratory under controlled conditions and an average of three specimens was tested and values are recorded.

Table 4. Mix proportions. (Self-Elaboration).

\begin{tabular}{lccccccc}
\hline \multirow{2}{*}{ Raw materials } & \multicolumn{7}{c}{ Quble 4. Mix proportions. (Self-Elaboration). } \\
\cline { 2 - 8 } & CS-0 & CS-10 & CS-30 & CS-50 & CS-70 & CS-90 & CS-100 \\
\hline Cement & 400.00 & 413.00 & 413.00 & 413.00 & 400.00 & 413.00 & 413.00 \\
NFA & 799.00 & 599.25 & 399.5 & 0 & 799.00 & 599.25 & 0 \\
CS & 0 & 199.75 & 399.5 & 799.00 & 0 & 199.75 & 799.00 \\
20 mm NCA & 617.40 & 617.40 & 617.40 & 617.40 & 617.40 & 617.40 & 617.40 \\
10 mm NCA & 411.60 & 411.60 & 411.60 & 411.60 & 411.60 & 411.60 & 411.60 \\
Water & 180.00 & 186.00 & 186.00 & 186.00 & 180.00 & 186.00 & 186.00 \\
w/c ratio & 0.45 & 0.45 & 0.45 & 0.45 & 0.45 & 0.45 & 0.45 \\
\hline
\end{tabular}


Figure 4. Normal mixing approach. (Self-Elaboration).

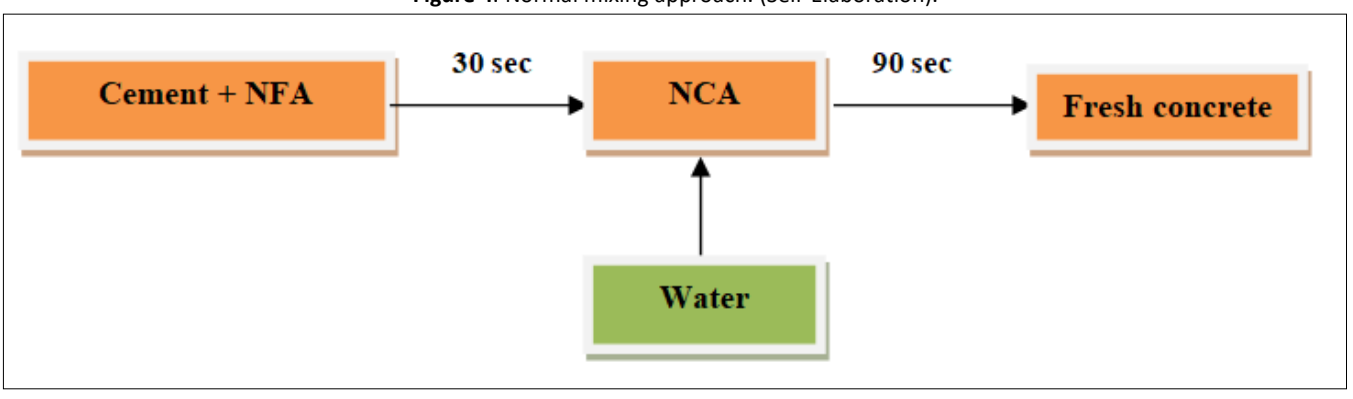

Results and discussions

\section{Material characterization}

The possibility of use of CS as a replacement to NFA was evaluated through XRD and SEM studies. Figure 5 shows the XRD patterns of NFA and CS used in the study. The maximum peaks in the NFA that promotes the C-S-H formation as $\mathrm{SiO}_{2}$ was also observed in the $\mathrm{CS}$. In additions, the other peak of $\mathrm{Fe}_{2} \mathrm{O}_{3}$ was observed due to the traces of iron ore formed during the production of copper. Figure 6 shows the microstructure of CS and NFA. From the visual observation and micro structural images, the angularity of CS was found to be equivalent to that of NFA that indicates the suitability of utilization of CS as replacement to NFA in the concrete.

Figure 5. XRD patterns (a) NFA (b) CS. (Self-Elaboration)
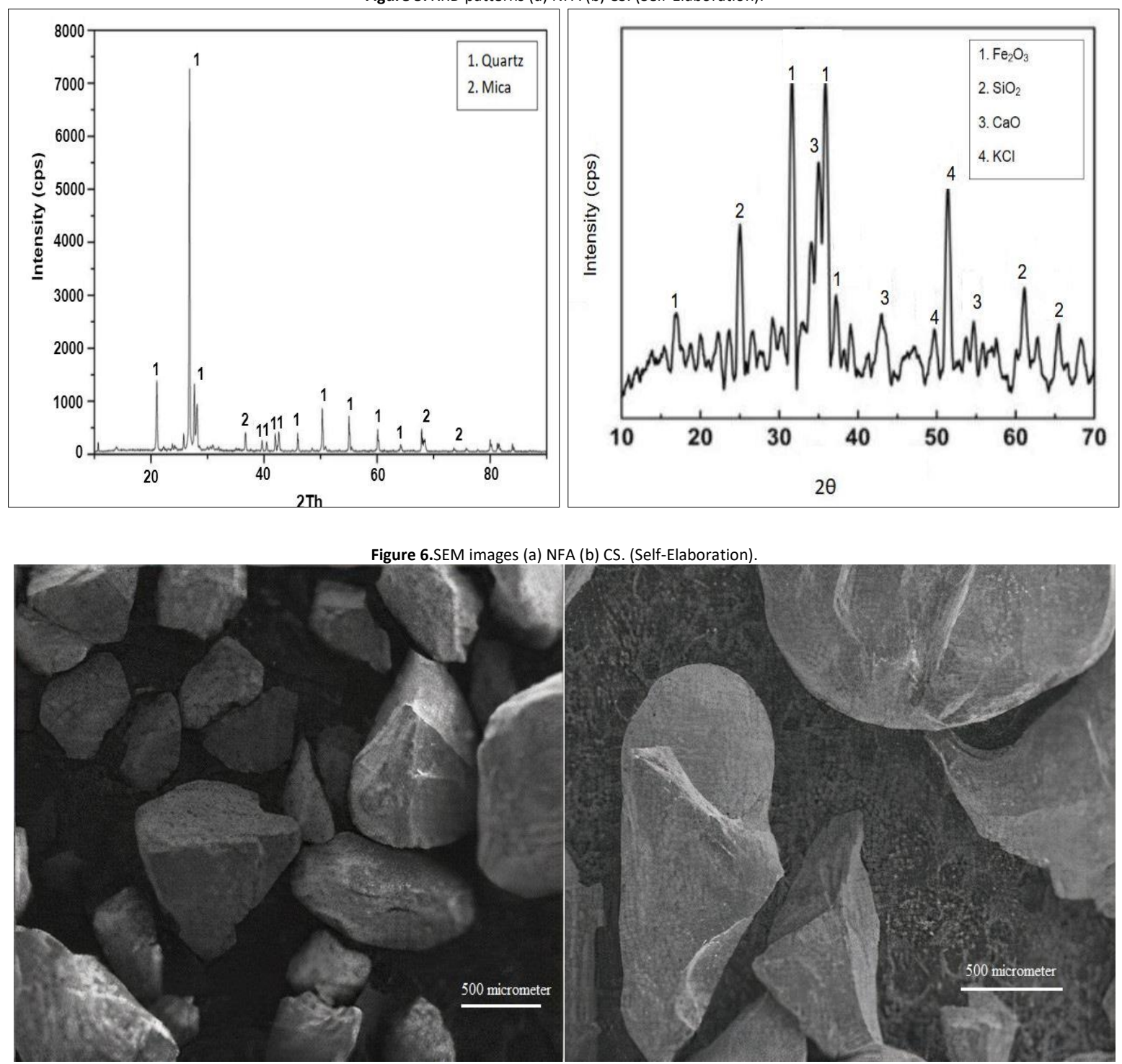


\section{Workability}

The degree of workability of the concrete with various proportions of CS is shown in the Figure 7. It is observed that as the percentage of CS increases, the compaction factor increases. The compaction factor of CS -0 and CS - 100 was found to be 0.82 and 0.96 . The lower absorption characteristics of CS results in segregation and bleeding of concrete mixes that is due to the available free water remains after hydration (Tamil selvi et al. 2014, Bhoi et al. 2018). However, the segregation and the bleeding in the concrete mixtures are observed when the replacement of CS exceeds $50 \%$. The common measure of addition of excess cement during placement has overcome the effect of segregation and bleeding.

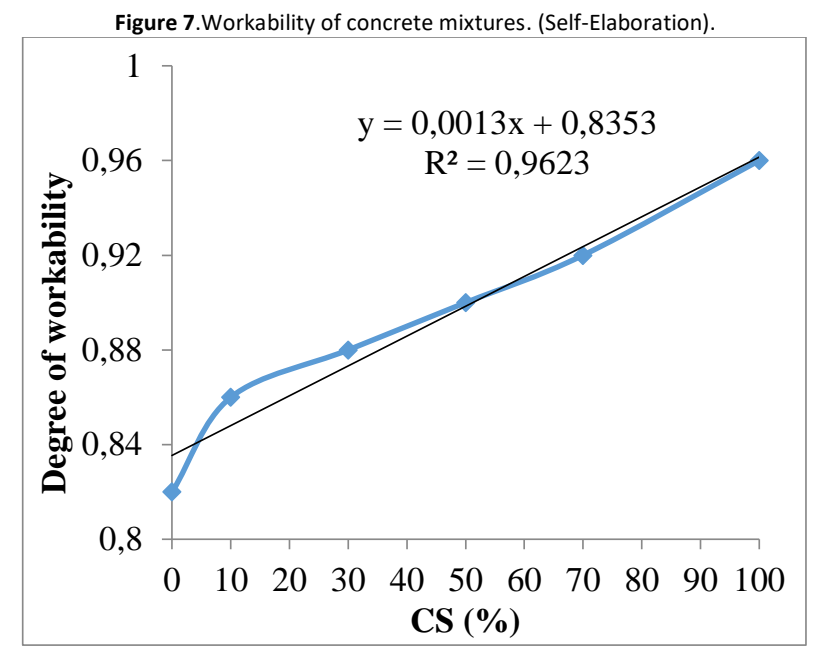

\section{Density}

The density of the concrete with various proportions of CS is shown in the Figure 8. It is observed that as the CS increases, the density of the concrete increases. The density of CS -0 at 28 days was found to be $2480 \mathrm{~kg} / \mathrm{m} 3$. The density of the $\mathrm{CS}-100$ was $2700 \mathrm{~kg} / \mathrm{m3}$ and it is found to be increased by $8.14 \%$ compared to CS - 0. The density of CS - 50 was $2569 \mathrm{~kg} / \mathrm{m} 3$ and it is found to be increased by $3.46 \%$ compared to CS -0 . Such increase in the density may be ascribed to the increase in the specific gravity of the CS particles.

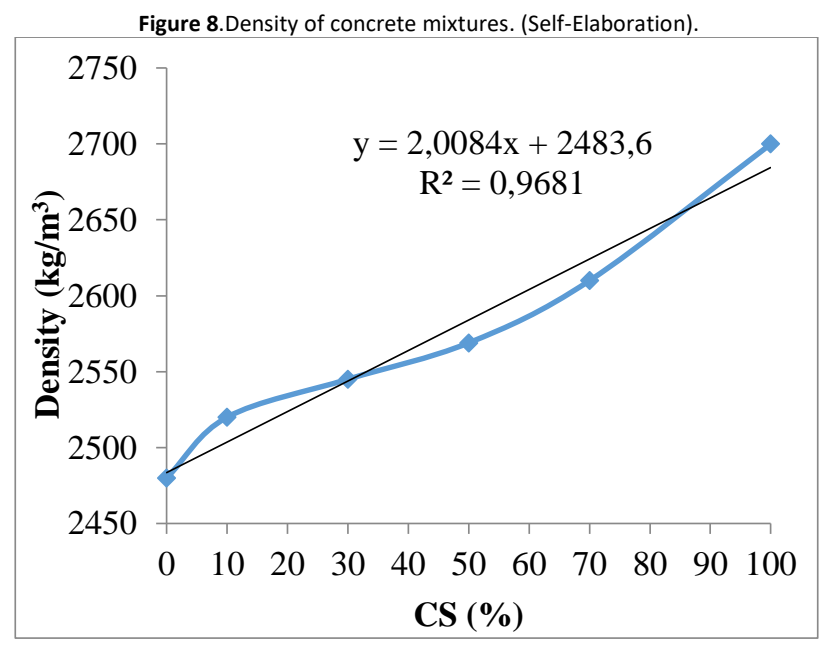

\section{Compressive strength}

The compressive strength of the concrete with various proportions of CS is shown in the Figure 9. It is observed that increase in the CS beyond 50\% decreases the compressive strength of the concrete. The optimal level of replacement of CS in the concrete was found to be $50 \%$ with strength of $47.07 \mathrm{MPa}$ at 28 days. The concrete mixes CS $-10, \mathrm{CS}-30$, CS -50 shows a $1.57 \%, 4.46 \%$ and $8.20 \%$ increase in the compressive strength compared to CS -0 at 28 days. The increase in the strength may be attributed to the surface texture of the CS with properties equivalent to that of NFA. However, CS -70 and CS -100 shows $4.90 \%$ and $7.12 \%$ decrease in the strength compared to CS -0 at 28 days. Such decrease may be ascribed to the increase in the porosity of the concrete mixes resulting from the increase in the replacement of CS (Tamil selvi et al. 2014, Bhoi et al. 2018). Furthermore, the strength of the CS - 10, CS - 30, CS - 50 
shows $3.43 \%, 5.82 \%, 9.14 \%$ more compared to CS -0 at 90 days. Also, the strength of the CS -70 and CS -100 was only $0.44 \%$ and $1.59 \%$ lesser compared to CS -0 at 90 days. Increased curing reduces the pore connectivity in the concrete and thus enhancing the strength of the concrete (Al-Jabri et al. 2009, Wu et al. 2010).

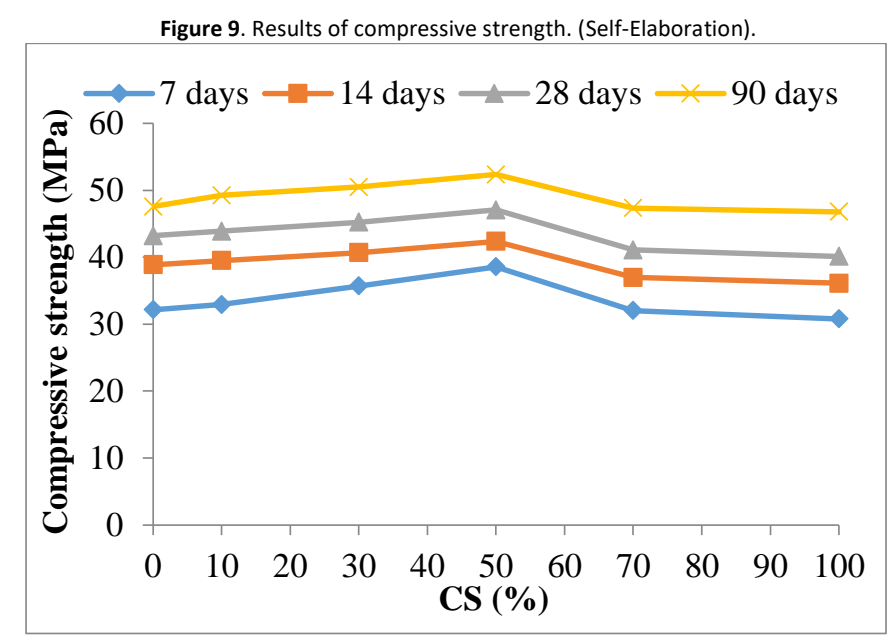

\section{Tensile strength}

The tensile strength of the concrete with various proportions of CS is shown in the Figure 10. Increase in the CS beyond $50 \%$ decreases the tensile strength of the concrete. The concrete mixes CS - 10, CS - 30, CS - 50 shows a $0.76 \%, 2 \%$ and $3.92 \%$ increase in the tensile strength compared to CS -0 at 28 days. However, CS -70 and CS -100 shows $2.55 \%$ and $3.82 \%$ decrease in the strength compared to CS -0 at 28 days. Furthermore, the strength of the CS - 10, CS - 30, CS 50 shows $1.67 \%, 2.83 \%, 4.41 \%$ more compared to CS -0 at 90 days. Also, the strength of the CS -70 and CS -100 was only $0.24 \%$ and $0.97 \%$ lesser compared to CS -0 at 90 days.

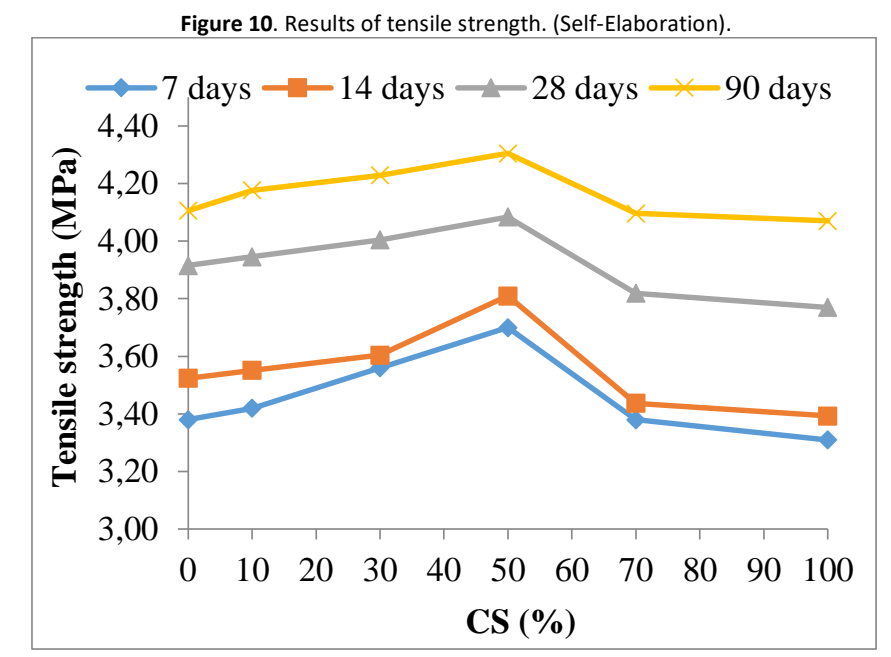

\section{Flexural strength}

The flexural strength of the concrete with various proportions of CS is shown in the Figure 11. Increase in the CS beyond $50 \%$ decreases the flexural strength of the concrete decreases. The concrete mixes CS - 10, CS - 30, CS - 50 shows a $0.86 \%, 2.33 \%$ and $4.16 \%$ increase in the tensile strength compared to CS -0 at 28 days. However, CS -70 and CS -100 shows $2.39 \%$ and $3.69 \%$ decrease in the strength compared to CS -0 at 28 days. Furthermore, the strength of the CS $10, \mathrm{CS}-30, \mathrm{CS}-50$ shows $1.62 \%, 2.81 \%, 4.73 \%$ more compared to CS -0 at 90 days. Also, the strength of the CS -70 and CS -100 was only $0.21 \%$ and $0.83 \%$ lesser compared to CS -0 at 90 days. 
Figure 11. Results of flexural strength. (Self-Elaboration).

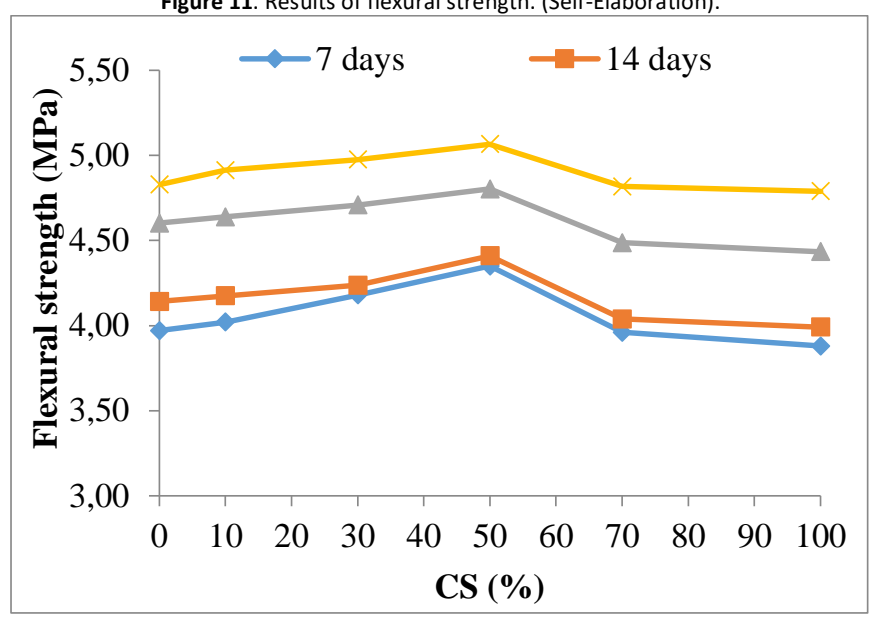

\section{Durability properties}

The durability properties of the concrete with various proportions of CS are shown in the Figure 12 . The concrete mixes CS -10, CS -30 , CS -50 shows a $5.26 \%, 10.52 \%, 19.4 \%$ decrease in the water absorption compared to CS -0 at 56 days. However, CS -70 and CS -100 shows $5.94 \%$ and $16.11 \%$ increase in the surface water absorption compared to CS -0 at 56 days. Replacement of CS beyond $50 \%$ increases the water absorption of the concrete due to the more un reacted water molecules in the concrete mixtures resulting from the low water absorption of the CS. The concrete mixes CS $10, C S-30, C S-50$ shows a $16.21 \%, 24.32 \%, 35.13 \%$ decrease in the porosity compared to CS -0 at 56 days. However, CS -70 and CS -100 shows $16.3 \%$ and $25.04 \%$ increase in the porosity compared to CS -0 at 56 days. The results of the porosity are proportionate with the results of the water absorption, as the pore volume increases the water absorption of the concrete increases. The rate of chloride ingression through the concrete mixtures depends on the porosity of the hardened concrete specimens (Saraswathy et al. 2014, Rajasekar et al. 2019). The resistivity of CS - 10, CS - 30, CS - 50 to chloride ions was $13.51 \%, 24.32 \%, 35.13 \%$ more compared CS -0 whereas the resistivity of CS $-70, C S-100$ was $13.95 \%, 19.56 \%$ less compared to CS -0 . The durability properties of the concrete were better with the replacement of CS up to $50 \%$. With higher replacement, due to lower water absorption of CS, the unreacted water molecule content increases. Upon hardening, the water molecules evaporate leaving pores behind and thus increasing the porosity of the concrete. As the water absorption and chloride ingression are direct dependent of porosity, increase in the porosity increases the water absorption and decreases the chloride resistivity (Wu et al. 2010, Caliskan et al. 2004).

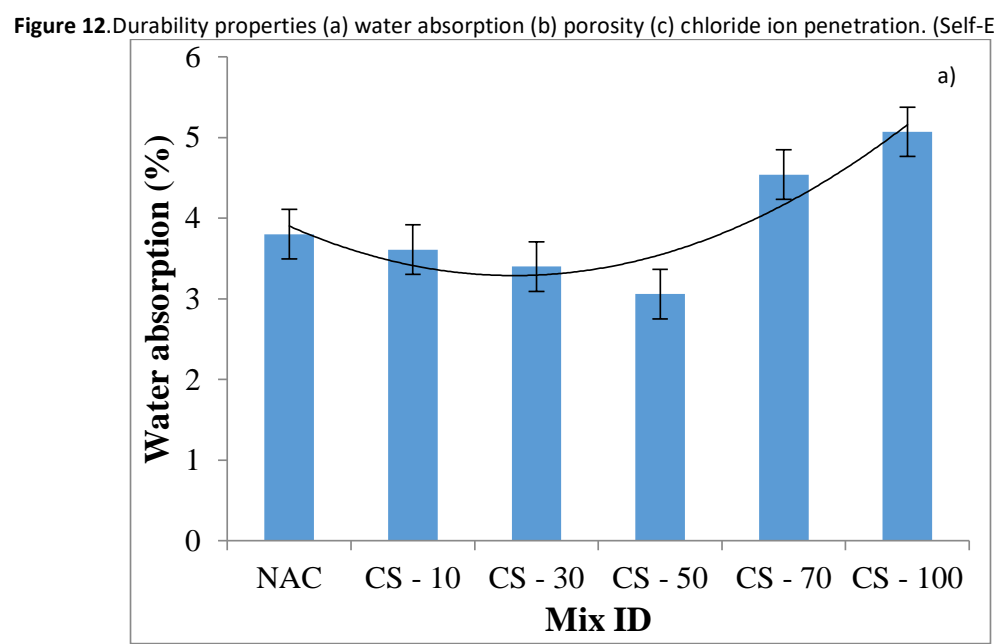



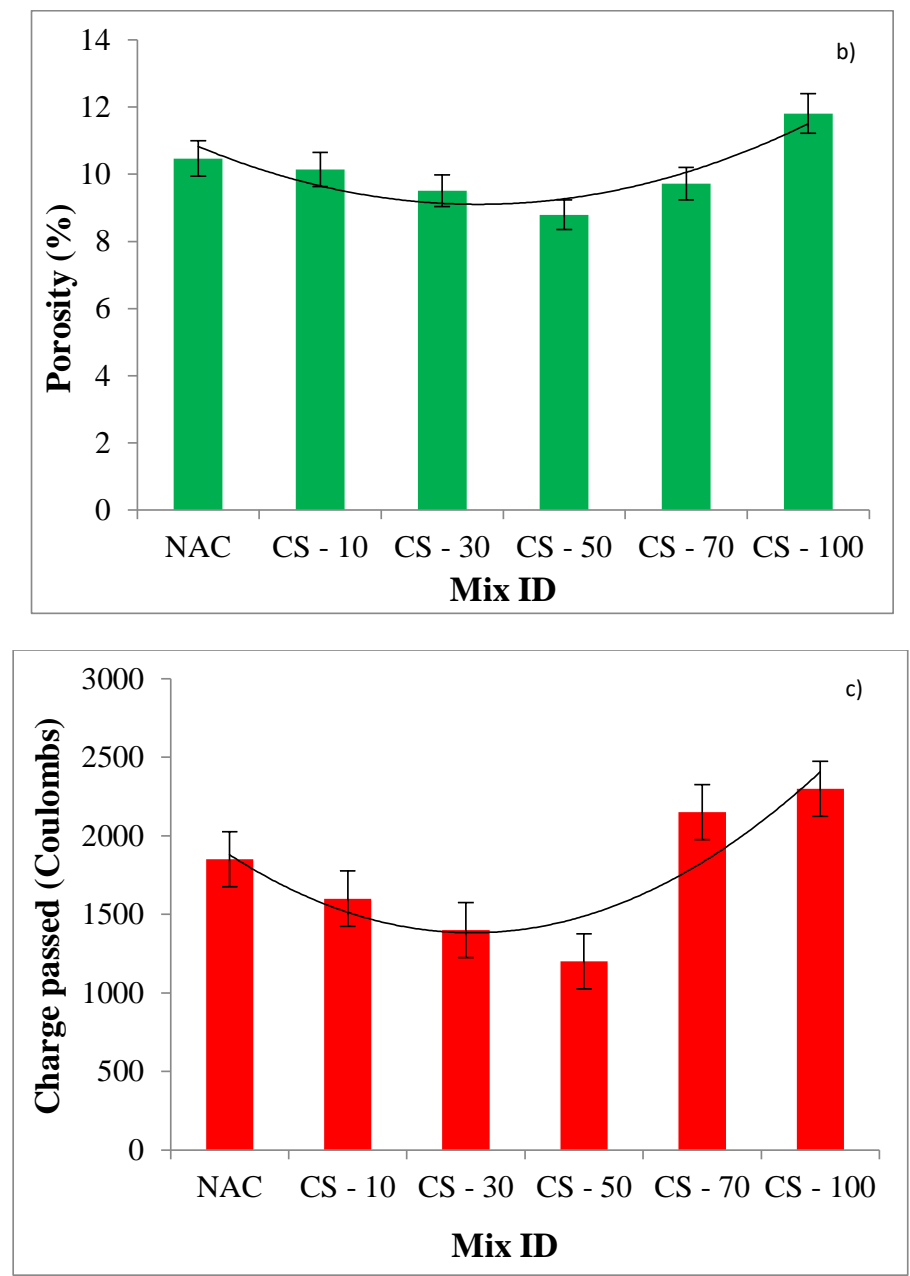

\section{Microstructure analysis}

Figure 13 shows the microstructure analysis of hardened CS - 0, CS - 50 and CS - 100 specimens. The improved compressibility and reduced pore volume of the CS enhanced the strength and durability properties of CS -50 . However, micro-pores are evident in CS - 100 that affects the strength and durability properties of the concrete. The interconnectivity of micro-pores increases the progression of micro-cracks and thus leading to the deterioration of the concrete (Bhoi et al. 2018). Also, upon higher replacement, the CS does not bind properly with cement matrix due to its increased specific surface area and hence reducing the strength of the concrete. Dense micro-structure could be observed in NAC and CS - 50 and so responsible for the enhanced properties of concrete compared to CS - 100 .

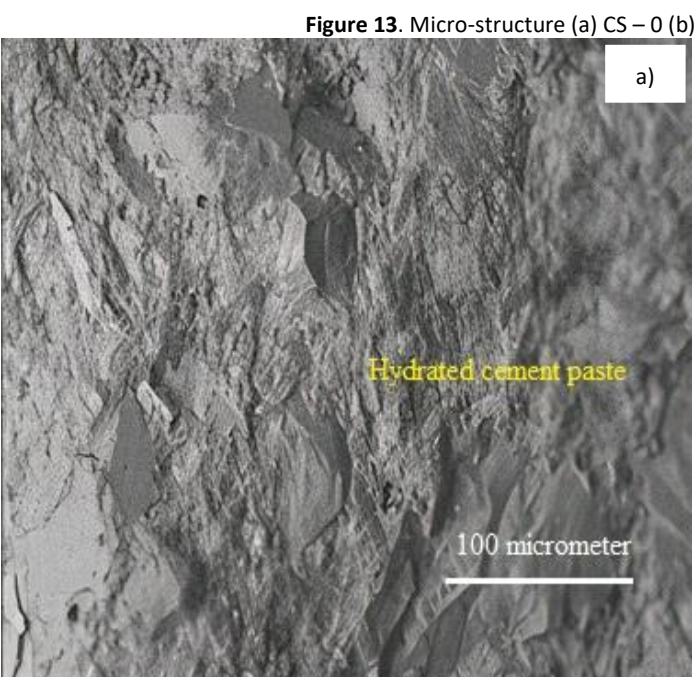

(a)

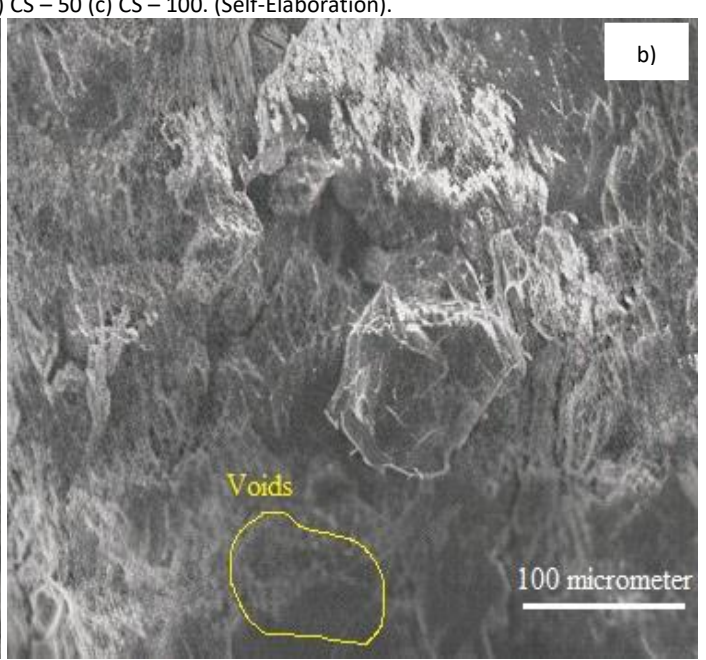

(b) 


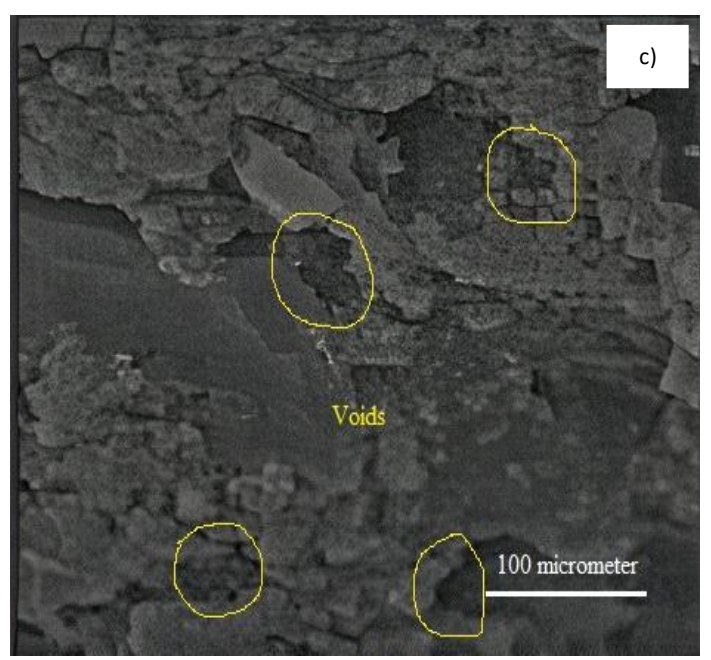

The use of CS as a suitable replacement to NFA was analyzed through fresh, hardened and durability properties. The following conclusions are drawn as follows:

- The increased specific gravity, lower water absorption and improved particle packing increased the replacement levels of CS in the concrete.

- The fresh property of the concrete increases with the increase in the utilization of CS due to its lower water absorption.

- The optimum level of replacement of CS was observed to be $50 \%$. The concrete mix CS - 50 shows $8.20 \%$, $3.92 \%$ and $4.16 \%$ increase in the compressive strength, tensile strength and flexural strength compared to CS -0 at 28 days. Similarly, the CS -50 shows $9.14 \%, 4.41 \%$ and $4.73 \%$ increase in the compressive strength, split tensile strength and flexural strength compared to CS - 0 at 90 days.

- The water absorption and porosity of CS -50 was $19.4 \%$ and $13.53 \%$ lesser compared to CS -0 at 56 days. Perhaps, the water absorption and porosity of CSC -100 was $16.11 \%$ and $25.04 \%$ more compared to CS -0 at 56 days.

- The chloride resistivity of CS - 0 and CS - 50 was higher whereas chloride resistivity of CS - 100 was lower compared to all other mixes.

The research provides findings on the feasibility of utilization of CS as substitution to NFA in the concrete. The study indicates that $50 \%$ replacement of CS improves the fresh, hardened and durability properties of the concrete. Also, improved curing enhances the strength and durability properties of the concrete that is equivalent to that of normal aggregate concrete. This research could overlay the predicament on the shortage of NFA in the construction and dumping of the CS. 
Al-Jabri, K. S., Al-Saidy, A. H., \& Taha, R. (2011). Effect of copper slag as a fine aggregate on the properties of cement mortars and concrete. Construction and Building Materials, 25(2), 933-938.

Al-Jabri, K. S. (2006). Copper slag as fine aggregate in high-performance concrete, High-performance structures and materials III. WIT Transactions on the Built Environment, 85, 381-389.

Aggarwal, P., Aggarwal, Y., \& Gupta, S. M. (2007). Effect of bottom ash as replacement of fine. Asian Journal of Civil Engineering (Building and Housing), $8(1), 49-62$.

Al-Bawi, R.K., Kadhim, I. T., \& Al-Kerttani, O. (2017). Strengths and failure characteristics of self-compacting concrete containing recycled waste glass aggregate. Advances in Materials Science and Engineering, vol. 2017, Article ID 6829510, 1-12.

Al-Jabri, K. S., Hisada, M., Al-Oraimi, S. K., \& Al-Saidy, A. H. (2009). Copper slag as sand replacement for high performance concrete. Cement and Concrete Composites, 31(7), 483-488.

Ambily, P. S., Umarani, C., Ravisankar, K., Prem, P. R., Bharatkumar, B. H., \& lyer, N. R. (2015). Studies on ultra high performance concrete incorporating copper slag as fine aggregate. Construction and Building Materials, 77, 233-240.

Andrade, L.B., Rocha, J.C., \& Cheriaf, M. (2009). Influence of coal bottom ash as fine aggregate on fresh properties of concrete. Construction and Building Materials, 23(2), 609-614.

ASTM C1202-19, Standard Test Method for Electrical Indication of Concrete's Ability to Resist Chloride Ion Penetration, ASTM International, West Conshohocken, PA, 2019, www.astm.org

ASTM C39 / C39M-21, Standard Test Method for Compressive Strength of Cylindrical Concrete Specimens, ASTM International, West Conshohocken, PA, 2021, www.astm.org

ASTM C618-19, Standard Specification for Coal Fly Ash and Raw or Calcined Natural Pozzolan for Use in Concrete, ASTM International, West Conshohocken, PA, 2019, www.astm.org

ASTM C642-13, Standard Test Method for Density, Absorption, and Voids in Hardened Concrete, ASTM International, West Conshohocken, PA, 2013, www.astm.org

Bai, Y., Darcy, F., \& Basheer, P. A. M. (2005). Strength and drying shrinkage properties of concrete containing furnace bottom ash as fine aggregate. Construction and Building Materials, 19(9), 691-697.

Bingöl, Ş., Bilim, C., Duran Atiş, C., Durak, U., Ilkentapar, S., \& Karahan, O. (2020). An investigation of resistance of sodium meta silicate activated slag mortar to acidic and basic mediums. Revista de la construcción, 19(1), 127-133

BS 1882 Part (2), Method for making test cubes from the fresh concrete, British standards, UK, London, 1983.

Caliskan, S., \& Behnood, A. (2004). Recycling copper slag as coarse aggregate: Hardened properties of concrete. Proceedings of 7th International Conference on Concrete Technology in Developing Countries, Kuala Lumpur, Malaysia, 91-98.

Ghafoori, N., J. \& Bucholc, J. (1996). Investigation of lignite-based bottom ash for structural concrete. Journal of Materials in Civil Engineering, 8(3), 128-137.

Gökçe, M., \& Şimşek, O. (2021). The effect of calcite and blast furnace slag on the rheology properties of self-compacting concrete in meso and macro scales. Revista de la construcción, 20(1), 190-204.

IS 2386 Part (3), Method of test for aggregates for concrete, Bureau of Indian Standards, India, 1963.

IS 516, Method of test for strength for concrete, Bureau of Indian Standards, India, 1959.

IS 5816, Method of test for splitting tensile strength for concrete, Bureau of Indian Standards, India, 1999

Mahes babu, \& K., Ravitheja, A. (2019). Effect of copper slag as fine aggregate replacement in high strength concrete. Materials today: Proceedings, $19,409-414$.

Onprom, P., Chaimoon, K., \& Cheerarot, R. (2015). Influence of bottom ash replacements as fine aggregate on the property of cellular concrete with various foam contents. Advances in Materials Science and Engineering, vol. 2015, Article ID 381704, 1-11.

Patil, M. V., \& Patil, Y. D. (2020). Effect of copper slag and granite dust as sand replacement on the properties of concrete. Materials Today: Proceedings, Online first. doi:10.1016/j.matpr.2020.10.029.

Prem, P. R., Verma, M., \& Ambily, P. S. (2018). Sustainable cleaner production of concrete with high volume copper slag. Journal of Cleaner Production, 193, 43-58.

Rajasekar, A., Arunachalam. K., \& Kottaisamy, M. (2019). Assessment of strength and durability characteristics of copper slag incorporated ultra high strength concrete. Journal of Cleaner Production, 208, 402-414.

Saraswathy, V., Karthick, S., \& Muralidharan, S. (2014). Corrosion and leaching studies in blended copper slag mortar. Journal of Engineering and Technology, 4(1), 29-37.

Tamil selvi, P., Lakshmi Narayani, P., \& Ramya, G. (2014). Experimental Study on Concrete Using Copper Slag as Replacement Material of Fine Aggregate. Journal of Civil and Environmental Engineering, 4, 1-6. 
Tripathi, B., \& Chaudhary, S. (2016). Performance based evaluation of ISF slag as a substitute of natural sand in concrete. Journal of Cleaner Production, $112,672-683$

Usa Kranti, J., Naga Sai, A., Rama Krishna, A., \& Srinivasu, K. (2020). An experimental investigation on effect of durability on strength properties of M40 grade concrete with partial replacement of sand with copper slag. Materials Today: Proceedings, Online first. https://doi.org/10.1016/j.matpr.2020.09.767.

Wu, W., Zhang, W., \& Ma, G. (2010). Optimum content of copper slag as a fine aggregate in high strength concrete. Material design, 31(6), 28782883.

Zhu, Z., Li, B., \& Zhou, M. (2015). The influences of iron ore tailings as fine aggregate on the strength of ultra-high performance concrete. Advances in Materials Science and Engineering, vol. 2015, Article ID 412878, 1-6. 